\title{
EXPRESSÃO PROTÉICA DIFERENCIAL ENTRE PLÂNTULAS APOMÍTICAS E ZIGÓTICAS DE CITROS ${ }^{1}$
}

\author{
CRISTINA LACERDA SOARES PETRAROLHA SILVA², MARCOS ANTÔNIO MACHADO \\ ELIANA GERTRUDES MACEDO LEMOS ${ }^{4}$
}

\begin{abstract}
RESUMO - Existem evidências do envolvimento de um ou poucos genes controlando o processo apomítico em citros; entretanto, a identidade destes genes, seus produtos e suas formas de atuação ainda não foram elucidados. Sendo as proteínas o produto final da expressão gênica, o processo apomítico pode ser investigado através do estudo da expressão protéica. A técnica da eletroforese bidimensional de proteínas foi empregada nesta pesquisa, objetivando a comparação de perfis protéicos de plântulas apomíticas e zigóticas de citros obtidas a partir de cruzamento entre Citrus sinensis L. Osb. cv. Pêra e Poncirus trifoliata cv. Rubidoux. Observou-se, nestes perfis bidimensionais, a ocorrência de três classes de proteínas: a primeira presente em ambos os perfis, a segunda exclusiva do perfil apomítico e a terceira exclusiva do perfil zigótico. Dentro da classe de proteínas compartilhada por ambos os perfis, observaram-se diferenças no nível de expressão entre zigóticos e apomíticos. A classe protéica exclusiva do perfil zigótico, provavelmente, está relacionada à expressão de genes herdados do parental masculino. Já dentre as proteínas exclusivas do perfil apomítico, podem estar proteínas relacionadas ao processo apomítico. O peso molecular e o ponto isoelétrico destas proteínas de expressão diferencial foram estimados e constituem, então, um banco de dados para futuros trabalhos de purificação e seqüenciamento das mesmas.
\end{abstract}

Termos para indexação: apomixia, citros, proteína, eletroforese bidimensional, RAPD.

\section{DIFFERENCIAL PROTEIN EXPRESSION AMONG ZYGOTIC AND APOMITIC SEEDLINGS OF CITRUS}

ABSTRACT - There are evidences that one or a few genes only regulate the apomictic process in citrus. However, the genes identities, their products and mode of action were not elucidated yet. As proteins are the final products of gene expression, the investigation of protein expression can lead to a better understanding of the apomictic process. In this research, the bidimensional protein electrophoresis technique was used to compare protein profiles from apomictic and zygotic seedlings of citrus. Three classes of proteins were observed based on bidimensional profiles: a) those observed in either one of the profiles, b) those exclusive to the apomictic profile, and c) those exclusive to the zygotic profile within that class of proteins shared by both profiles. Differences in the expression level were observed for apomitic or zygotic seedlings. The class of protein exclusive to the zygotic profile is probably related to the expression of genes inherited from the male parental. The proteins detected in the apomictic profile could be related to the apomictic process itself. The molecular weight and the isoelectric point of these differentially expressed proteins were also estimated and probably constitute an important data base for future work on purification and sequencing of these proteins.

Index terms: apomixis, citrus, protein, bidimensional electrophoresis, RAPD.

\section{INTRODUÇÃO}

O fenômeno da apomixia caracteriza-se pela reprodução assexuada por meio de sementes, onde um ou mais embriões são formados sem redução do número cromossômico e sem fertilização (Nogler, 1984). Os embriões apomíticos apresentam constituição genética idêntica à da planta genitora feminina e representam uma barreira à recombinação genética (Koltunow, 1993). O padrão de formação dos embriões em espécies apomíticas é freqüientemente indistinguível do seu relativo sexual (Nogler, 1984). O gênero Citrus apresenta apomixia facultativa, onde reprodução sexual e apomítica coexistem na mesma planta (Koltunow, 1993). Espécies apomíticas facultativas adaptaram-se evolutivamente, devido à capacidade de multiplicar as combinações genéticas vantajosas por meio da reprodução apomítica (Nijis \& Van Dijik, 1994).

Existem evidências de que a herança da embriogênese nucelar apomítica em Citrus é um caráter dominante, com o envolvimento de um lócus principal, que pode consistir de vários genes ligados entre si, codificando diversos elementos apomíticos (Cameron \& Soost, 1982; Dijk \& Damme, 2000). Entretanto, tais genes ainda não foram isolados, permanecendo ainda como incógnita a identificação de seus produtos e de suas funções. Modelos de ação gênica relacionados à apomixia facultativa sugerem que, uma vez que os genes apomíticos são acionados em uma célula nucelar específica, os elementos do processo sexual poderiam completar o evento. Informações nos tipos de genes expressos durante o desenvolvimento apomítico e sexual nos óvulos poderão indicar se os processos apomíticos são resultantes de genes

específicos relacionados à reprodução apomítica das plantas ou se a apomixia reflete alterações na regulação e expressão dos genes normalmente envolvidos na reprodução sexual (Koltunow, 1993; Koltunow et al., 1995). É improvável que o lócus responsável pelo evento apomítico envolva novas e distintas vias metabólicas (Koltunow et al., 1995). Uma possibilidade é que a reprodução apomítica seja uma conseqüência da expressão errônea de um gene, durante o curso dos eventos sexuais no óvulo (Peacock, 1992; Koltunow, 1993). Outra hipótese é que o fenótipo apomítico seja decorrente da mutação deste alelo (Koltunow et al., 1995).

Em Citrus, a apomixia possibilita a uniformidade das cultivares, a fixação da epistasia e da heterose, e a eliminação de vírus e viróides (Davies \& Albrigo, 1994). Entretanto, a apomixia é o maior obstáculo para a produção sistemática de híbridos, visto que muitas cultivares produzem quase que somente embriões nucelares (apomíticos), os quais podem ser muitos em uma única semente (Cameron \& Soost, 1982).

Por outro lado, a engenharia genética oferece ferramentas que possibilitam a introdução do comportamento apomítico em culturas agrícolas de reprodução sexuada, o que tem sido citado na literatura como a "tecnologia da apomixia". Através desta tecnologia, seria possível a fixação da heterose, através de sucessivas gerações, via semente (Nijis \& Van Dijik, 1994). Outras vantagens seriam conseguidas, como, por exemplo, a transformação direta de genótipos superiores em cultivares e a eliminação da transmissão de vírus através de propagação vegetativa. Entretanto, antes se faz necessário que os genes que controlam o fenômeno apomítico, sejam elucidados (Dijk \& Damme, 2000).

\footnotetext{
${ }^{1}$ (Trabalho 058/2003). Recebido: 30/03/2003. Aceito para publicação: 07/01/2004.

${ }^{2}$ Professora de Genética da Faculdade de Medicina Veterinária da FEA. R. Amazonas, 571 Andradina-SP. CEP 16901-160, e-mail: hrsilva @agr.feis.unesp.br.

${ }^{3}$ Pesquisador Científico, Instituto Agronômico, Centro APTA Citros "Sylvio Moreira”. Rod. Anhanguera, km 158 Cordeirópolis-SP. CEP- 13490-970. e-mail: marcos@centrodecitricultura.br.

${ }^{4}$ Professora Titular de Bioquímica do Depto de Tecnologia da FCAV/UNESP, Depto de Tecnologia. Via de Acesso Prof. Paulo D. Castellane. Jaboticabal-SP. CEP 14884-900. E-mail:egerle@fcav.unesp.br.
} 
Uma das formas de estudar os mecanismos moleculares do processo apomítico, é por meio da comparação de perfis protéicos de embriões zigóticos e apomíticos, buscando-se a existência de diferentes proteínas envolvidas no desenvolvimento apomítico. Atualmente, a técnica de maior resolução para a separação de proteínas é a eletroforese bidimensional (O'Farrell, 1975), a partir da qual se produz um mapa ou perfil protéico global. Estes perfis compõem as bases para o estudo de proteomas, ou seja, identificação sistemática de proteínas codificadas pelo genoma (Lopez, 1999; Fey \& Larsen, 2001).

O presente trabalho teve por objetivo a comparação de perfis protéicos bidimensionais de plântulas apomíticas (nucelares) de Citrus sinensis e de plântulas zigóticas de citranges $(C$. sinensis X Poncirus trifoliata), de modo a produzir um banco de dados de proteínas de expressão diferencial de plântulas apomíticas.

\section{MATERIAL E MÉTODOS}

Foram utilizados embriões zigóticos e apomíticos (nucelares) resultantes do cruzamento controlado entre laranja-doce $(C$. sinensis L. Osb. $c v$. Pêra) e P. trifoliata $c v$. Rubidoux, provenientes do Banco Ativo de Germoplasma do Centro de Citricultura Sylvio Moreira / IAC Cordeirópolis - SP. C. sinensis foi utilizada como genitor feminino e $P$. trifoliata como genitor masculino.

\section{Cultura in vitro dos embriões}

Os embriões foram utilizados após 51 dias da polinização controlada. As sementes resultantes dos cruzamentos foram banhadas por 15 min em solução estéril de hipoclorito de sódio $0,5 \%$ e detergente Extran 1\%. Retiraram-se os tegumentos e banharam-se em solução estéril de hipoclorito de sódio $0,5 \%$ por $10 \mathrm{~min}$. As sementes foram então lavadas em água destilada autoclavada por $1 \mathrm{~min}$, por três vezes. Os embriões foram isolados em ambiente estéril, com auxílio de lupa, e transferidos para tubos de ensaio, contendo $15 \mathrm{~mL}$ de meio MT (Murashige \& Tucker, 1969), suplementados com $50 \mathrm{~g} / \mathrm{L}$ de sacarose e $6 \mathrm{~g} / \mathrm{L}$ de phytagel, e foram mantidos no escuro com temperatura controlada de $27+/-1^{\circ} \mathrm{C}$, até o estádio de plântula.

\section{Identificação de embriões zigóticos e nucelares}

Empregou-se a técnica de RAPD para gerar marcadores que diferenciassem a progênie zigótica da nucelar. A extração de DNA foi baseada no método proposto por Saghai-Maroof et al. (1984) e a reação RAPD foi feita com $30 \mathrm{ng}$ de DNA total, tampão PCR 1X (GIBCO), $\mathrm{MgCl}_{2}$ $1,5 \mathrm{mM}$, dNTP $1 \mu \mathrm{M}$ de cada, Taq DNA Polimerase (GIBCO) $1 \mathrm{U}$, "primer" (fornecidos pela Britsh University of Columbia) $225 \mu \mathrm{M}, \mathrm{H}_{2} \mathrm{O}$ milli filtrada q.s.p. $20 \mu \mathrm{L}$. Para amplificação, utilizou-se um ciclo de $94^{\circ} \mathrm{C}$, por $2 \mathrm{~min}$, seguido de 36 ciclos de $94^{\circ} \mathrm{C}$, por $1 \mathrm{~min} ; 36^{\circ} \mathrm{C}$, por $2 \mathrm{~min} ; 72^{\circ} \mathrm{C}$, por $2 \mathrm{~min}$, e por fim a $72^{\circ} \mathrm{C}$, por $5 \mathrm{~min}$. Os produto das reações foram separados através de eletroforese $(90 \mathrm{~V}-1 \mathrm{~h} 30 \mathrm{~min})$ em gel de agarose $(1,5 \%$, dissolvida em Tampão TBE 1X - Tris $28 \mathrm{mM}$, ácido bórico $88 \mathrm{mM}$, EDTA $7 \mathrm{mM}, \mathrm{pH} 8,3)$ contendo brometo de etídio $(0,5 \mu \mathrm{g} / \mathrm{mL})$.

\section{Extração Protéica}

As plântulas foram maceradas em $\mathrm{N}_{2}$ líquido e, para cada $\mathrm{mg}$ de material macerado, acrescentaram-se $5 \mu \mathrm{L}$ de tampão de extração (4\% SDS, 2\% 2-mercaptoetanol, 20\% glicerol, $2 \mathrm{mM}$ phenylmethylsulfonyl fluoride em $10 \mathrm{mM}$ Tris-HCl pH 8,5), seguindo metodologia proposta por Hurkman \& Tanaka (1986). A quantificação foi realizada segundo o método de microensaio descrito por Bradford (1976).

\section{Focalização Isoelétrica ( $1^{\mathrm{a}}$ Dimensão)}

Utilizaram-se géis de poliacrilamida com gradientes imobilizados de pH 3-10 não linear (IPG strip- Amersham Pharmacia), os quais foram reidratados por $12 \mathrm{~h}$ com tampão de amostra (uréia $8 \mathrm{M}$, CHAPS 2\%, DTT 18 mM, IPG Buffer 0,5\% -Amersham Pharmacia Biotec), contendo $50 \mu \mathrm{g}$ de extrato protéico. Em seguida, cada gel foi submetido à corrente elétrica máxima de $50 \mu \mathrm{A}$, usando o seguinte programa: $500 \mathrm{~V}$ por $1 \mathrm{~h}, 1000 \mathrm{~V}$ por $1 \mathrm{~h}$ e $8000 \mathrm{~V}$ por $2 \mathrm{~h}$. Imediatamente após a focalização, os géis foram banhados em solução de equilíbrio (50mM Tris-HCl pH8,8, 6M uréia, 30\% glicerol, 2\% SDS, 64mM DTT), por 15 min, e imediatamente procedeu-se a segunda dimensão.

\section{SDS/PAGE (2 $2^{\text {a Dimensão) }}$}

A separação das proteínas através dos pesos moleculares foi conduzida segundo Laemmli (1970). Foram produzidos cinco géis de cada amostra para confirmação da reprodutividade. As proteínas foram reveladas com prata, utilizando-se de Silver Staining kit- Protein (Amersham-Pharmacia). As imagens dos géis foram digitalizadas por um escâner de transmitância com 300 dpi de resolução e analisadas pelo programa ImageMaster 2D v.3.01 (Amersham Pharmacia Biotech). Os espotes (proteínas isoladas) foram detectados automaticamente, e artefatos foram corrigidos manualmente. Os espotes foram quantificados em unidades de volume (área versus intensidade) e a normalização foi efetuada dividindo-se o volume de cada espote pela soma total dos volumes de todos os espotes, de forma que cada volume normalizado representa uma porcentagem do volume total. Para a determinação do peso molecular e do ponto isoelétrico (pI), utilizaramse padrões Amersham Pharmacia, os quais foram plotados em coordenadas y e x dos géis de segunda dimensão. Através do programa, elaboraram-se equações ajustadas por regressão de First-order LaGrande, que serviram para a determinação do peso molecular e do pI (ponto isoelétrico) de cada espote.

\section{RESULTADOS E DISCUSSÃO}

O cultivo in vitro dos embriões permitiu a padronização do estádio de desenvolvimento e a quantidade de material suficiente para trabalhar-se em nível molecular. Para a identificação da origem nucelar e zigótica da progênie, testaram-se inicialmente 24 "primers", buscandose polimorfismo suficiente para a diferenciação dos parentais e conseqüentemente da progênie. Verificou-se que o "primer" BC708 (5'GGGTTGTGGG3') produziu uma banda polimórfica de $667 \mathrm{pb}$ no perfil do parental masculino (Poncirus trifoliata). Desta forma, este "primer" foi empregado nas amostras da progênie, e apenas os indivíduos que apresentavam a banda de $667 \mathrm{pb}$ foram selecionados como zigóticos, e os demais como apomíticos (Figura 1). Somente após essa verificação procedeu-se à análise protéica.

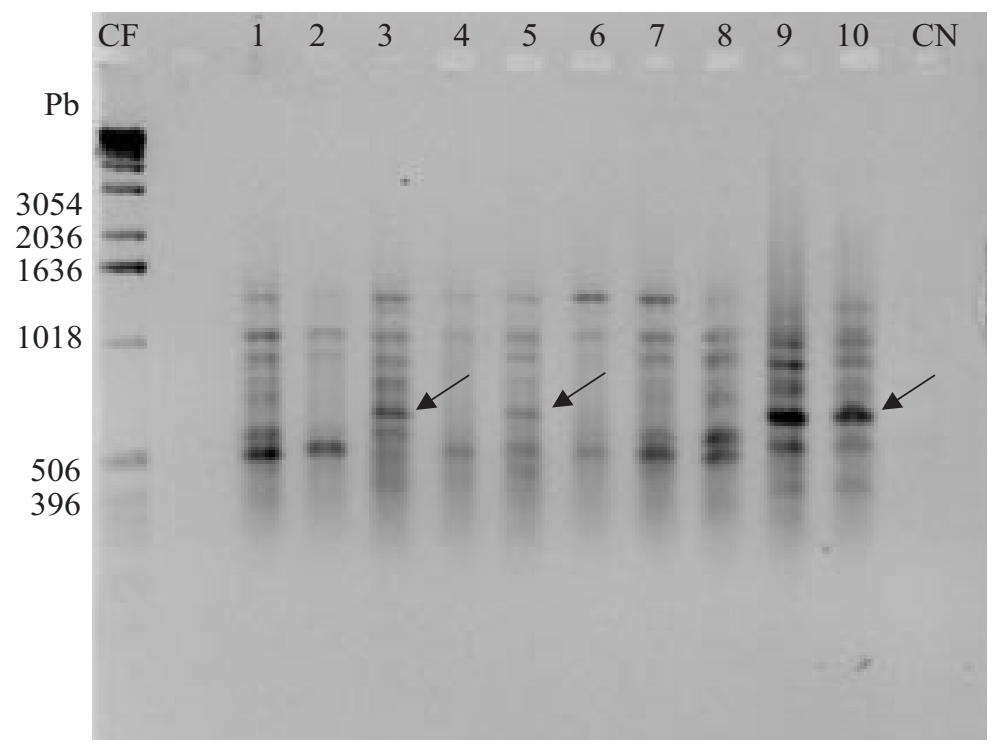

FIGURA 1- Perfil RAPD de plântulas de citros (canaleta 1; 2; 4; 6 e 7 progênie nucelar, canaletas 3 e 5 - progênie zigótica) e das plantas parentais (8- genitor feminino-Citrus sinensis, $9 \mathrm{e}$ 10- genitor masculino - Poncirus trifoliata). As setas indicam a banda polimórfica de $669 \mathrm{pb}$. CF- comprimento de fragmento; $\mathrm{CN}$ - controle negativo; $\mathrm{Pb}$ - pares de bases. 


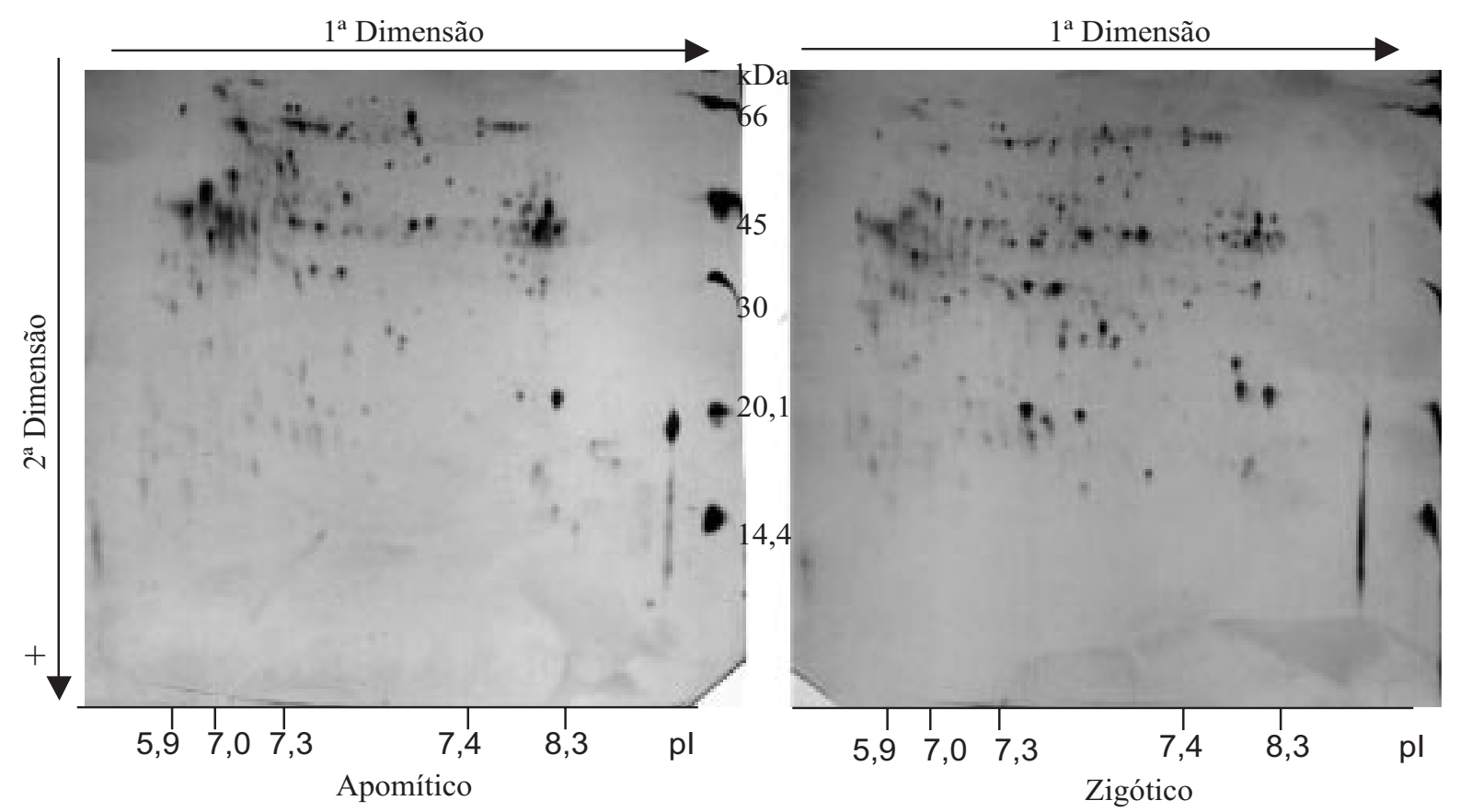

FIGURA 2 - Perfil bidimensional de proteínas de plântulas obtidas a partir de cruzamentos controlados entre Citrus sinensis L. Osb. cv. Pêra e Poncirus trifoliata $c v$ Rubidoux mantidas in vitro por 51 dias.

TABELA 1 - Proteínas expressas diferencialmente por plântulas apomíticas mantidas in vitro, oriundas do cruzamento de Citrus sinensis e Poncirus trifoliata.

\begin{tabular}{|c|c|c|c|c|c|c|c|c|c|c|c|}
\hline Espote & pI & PM (KDa) & Espote & pI & PM (KDa) & Espote & pI & PM (KDa) & Espote & pI & PM (KDa) \\
\hline 5 & 8,46 & 96,283 & 151 & 7,20 & 65,625 & 197 & 7,22 & 33,955 & 263 & 7,26 & 21,199 \\
\hline 11 & 7,04 & 76,901 & 152 & 7,09 & 63,635 & 199 & 7,41 & 45,353 & 264 & 7,43 & 20,525 \\
\hline 12 & 6,55 & 74,112 & 153 & 7,05 & 64,622 & 200 & 7,41 & 40,283 & 265 & 7,21 & 18,713 \\
\hline 17 & 7,43 & 71,865 & 154 & 6,98 & 80,660 & 206 & 7,59 & 45,422 & 266 & 7,29 & 18,945 \\
\hline 28 & 6,04 & 68,727 & 155 & 6,65 & 78,456 & 207 & 7,53 & 43,573 & 267 & 7,25 & 18,829 \\
\hline 30 & 7,41 & 66,540 & 156 & 6,65 & 76,901 & 211 & 7,63 & 43,040 & 268 & 6,02 & 37,994 \\
\hline 37 & 7,63 & 64,722 & 157 & 6,48 & 75,261 & 213 & 7,39 & 43,640 & 269 & 6,02 & 36,335 \\
\hline 40 & 7,43 & 64,028 & 158 & 6,51 & 75,030 & 216 & 7,71 & 45,703 & 270 & 6,21 & 36,001 \\
\hline 41 & 7,41 & 63,342 & 159 & 6,89 & 65,222 & 217 & 7,85 & 27,711 & 271 & 5,89 & 37,529 \\
\hline 42 & 7,41 & 62,953 & 160 & 6,96 & 64,722 & 221 & 7,96 & 13,733 & 272 & 6,47 & 38,881 \\
\hline 44 & 7,42 & 62,087 & 161 & 6,90 & 68,727 & 222 & 8,30 & 17,327 & 273 & 6,54 & 41,735 \\
\hline 45 & 7,39 & 60,856 & 164 & 6,80 & 53,228 & 223 & 8,32 & 17,897 & 274 & 6,90 & 33,695 \\
\hline 46 & 7,40 & 61,705 & 165 & 7,18 & 46,627 & 224 & 8,32 & 16,698 & 275 & 6,01 & 30,769 \\
\hline 47 & 7,42 & 61,515 & 166 & 7,20 & 48,159 & 225 & 8,31 & 16,751 & 277 & 6,37 & 44,045 \\
\hline 48 & 7,18 & 58,110 & 167 & 7,12 & 47,937 & 229 & 8,33 & 16,674 & 278 & 6,11 & 41,606 \\
\hline 49 & 7,39 & 56,871 & 168 & 7,16 & 48,606 & 230 & 8,31 & 33,385 & 279 & 6,80 & 26,137 \\
\hline 50 & 7,42 & 55,657 & 172 & 7,33 & 46,915 & 231 & 8,00 & 52,657 & 280 & 6,62 & 27,583 \\
\hline 51 & 7,15 & 54,977 & 173 & 7,29 & 48,159 & 232 & 7,87 & 52,738 & 281 & 6,37 & 25,305 \\
\hline 52 & 7,20 & 54,137 & 174 & 7,26 & 47,204 & 233 & 7,62 & 55,572 & 282 & 7,06 & 21,396 \\
\hline 54 & 7,40 & 51,852 & 175 & 7,20 & 44,045 & 234 & 7,53 & 53,887 & 283 & 6,99 & 19,598 \\
\hline 58 & 7,57 & 49,057 & 176 & 7,22 & 43,775 & 235 & 7,49 & 56,521 & 284 & 7,36 & 18,656 \\
\hline 63 & 7,88 & 45,493 & 178 & 7,20 & 53,145 & 241 & 7,39 & 62,374 & 286 & 7,01 & 16,218 \\
\hline 65 & 7,45 & 44,181 & 179 & 7,42 & 42,252 & 242 & 7,40 & 56,871 & 287 & 7,19 & 24,051 \\
\hline 68 & 7,29 & 43,040 & 180 & 7,38 & 42,187 & 243 & 7,40 & 58,468 & 288 & 7,01 & 24,237 \\
\hline 80 & 7,53 & 35,287 & 181 & 7,26 & 51,852 & 244 & 7,43 & 55,316 & 289 & 6,44 & 32,875 \\
\hline 81 & 7,81 & 34,589 & 182 & 7,27 & 55,146 & 245 & 7,43 & 58,829 & 290 & 6,32 & 33,129 \\
\hline 85 & 7,39 & 30,439 & 183 & 7,38 & 41,671 & 247 & 7,43 & 64,722 & 291 & 7,43 & 15,509 \\
\hline 90 & 7,56 & 22,825 & 184 & 7,02 & 43,040 & 248 & 7,43 & 51,614 & 293 & 7,98 & 28,011 \\
\hline 100 & 8,31 & 17,980 & 186 & 6,46 & 41,415 & 250 & 7,35 & 54,723 & 294 & 7,97 & 31,879 \\
\hline 143 & 7,00 & 64,921 & 187 & 6,70 & 45,144 & 251 & 7,38 & 57,753 & 296 & 8,24 & 12,736 \\
\hline 144 & 7,42 & 71,204 & 188 & 6,55 & 45,213 & 252 & 7,43 & 62,087 & 300 & 6,22 & 18,090 \\
\hline 145 & 7,42 & 72,979 & 193 & 7,01 & 35,835 & 254 & 7,43 & 50,281 & 301 & 6,08 & 14,718 \\
\hline 146 & 7,40 & 72,643 & 194 & 7,02 & 38,346 & 259 & 7,23 & 24,237 & 302 & 7,40 & 29,021 \\
\hline 148 & 7,30 & 66,643 & 195 & 7,16 & 37,298 & 261 & 7,14 & 19,239 & 304 & 7,39 & 19,933 \\
\hline 149 & 7,26 & 65,322 & 196 & 7,13 & 38,170 & 262 & 7,34 & 20,304 & 305 & 7,41 & 18,035 \\
\hline
\end{tabular}

Através da análise bidimensional das proteínas, pode-se identificar um total de 508 espotes protéicos, sendo que, no perfil da progênie apomítica, observou-se um número inferior ao observado no perfil da progênie zigótica, respectivamente, 217 e 291 (Figura 2). Grande parte das proteínas detectadas, provavelmente, constituam-se em proteínas de reserva, dada a fase de desenvolvimento em que o material se encontrava. Entretanto, entre elas, estão as proteínas cuja expressão ocorreu no período de embriogênese. A grande maioria das seqüências de mRNA produzidas durante o 
desenvolvimento do embrião são estocadas, principalmente, nos cotilédones, e persistem no estádio de plântulas, de maneira que apenas pequenas alterações qualitativas podem ocorrer (Goldberg et al., 1989). Dentre os genes que são expressos na embriogênese, estão os que determinarão a arquitetura básica da planta (Thomas, 1993).

Observou-se que 77 espotes são comuns a ambos os perfis (apomítico e zigótico), perfazendo uma similaridade de 26,5\% entre eles. Tais espotes correspondem a proteínas resultantes da expressão de genes comuns aos dois tipos de embriões. Na comparação dos perfis, verificou-se que a maioria das proteínas coincidentes apresentou valores próximos de quantificação, demonstrando nível semelhante de expressão protéica. Entretanto, também se verificaram-se diferenças no nível de expressão de genes comuns à progênie zigótica e nucelar. Como exemplo disto, pode-se citar a proteína de 21,7 KDa e pI 6,4 (valores estimados), a qual apresentou um volume normalizado aproximado de 0,5 no perfil nucelar e 3,9 no perfil zigótico. Outro exemplo é a proteína de $49 \mathrm{KDa}$ e pI 6,4 (valores estimados), apresentando volume normalizado de 3,9 no perfil nucelar e 0,2 no perfil zigótico. Provavelmente, as proteínas comuns entre os dois perfis são resultantes da expressão de genes relacionados a processos metabólicos essenciais à manutenção ou desenvolvimento do embrião/plântula. Uma explicação para estas diferenças nos níveis de expressão seria o fato de que, quando os embriões foram retirados de sementes para serem cultivados in vitro, se encontravam em diferentes estádios de desenvolvimento. Ou seja, aqueles embriões que se encontravam em fase mais desenvolvida, já haviam iniciado o processo de acúmulo ou degradação de proteínas de reserva, que, segundo Goldberg et al. (1989), tem início na fase de expansão celular do embrião. $\mathrm{O}$ embrião, quando em desenvolvimento in vivo, recebe estímulos das estruturas da semente para expressão protéica (Koltunow et al., 1996). Embriões apomíticos de citros desenvolvidos in vivo expressam a proteína de reserva citrina cerca de 8 a 9 vezes mais que em embriões somáticos desenvolvidos in vitro (Koltunow et al., 1996). Em Brassica napus, também ocorre diferença no nível de expressão quando se comparam embriões zigóticos e não zigóticos cultivados in vitro (Crouch, 1982).

Nos perfis das plântulas zigóticas, observaram-se 214 espotes que não estão presentes nos perfis das plântulas apomíticas. Já nos perfis da progênie apomítica, observaram-se 140 espotes ausentes nos perfis da progênie zigótica (Tabela1). No geral, essas proteínas diferenciais variaram em uma faixa de peso molecular entre 12,7 KDa e 96,2 KDa e em uma faixa de pI de 6,0 a 8,4. Pode-se considerar que parte das diferenças observadas entre as plantas de origem zigótica e nucelar pode estar relacionada ao fato de estar-se comparando os embriões nucelares de uma espécie (C. sinensis) com os embriões zigóticos de um híbrido intergenérico $(C$. sinensis $\mathrm{x} P$. trifoliata), e, portanto, diferentes proteínas podem ser conseqüência de estar-se trabalhando com diferentes conjuntos gênicos. Entretanto, no conjunto de proteínas de expressão diferencial, estão proteínas candidatas ao envolvimento com o processo apomítico. Obviamente, apenas pequena parte deve estar diretamente relacionada com a apomixia, uma vez que os modelos moleculares do processo apomítico preconizam o envolvimento de um ou de poucos genes (Parlevliet \& Cameron, 1959; Iwamasa et al., 1967; Dijk \& Damme, 2000).

O total conhecimento da identidade destas proteínas diferencialmente expressas pela progênie apomítica só é possível através de seqüenciamento das mesmas e posterior busca de similaridade em banco de dados. Entretanto, para utilizar-se tal tecnologia, é pré-requisito indispensável o conhecimento do perfil diferencial destas proteínas, assim como de algumas características bioquímicas, como peso molecular e ponto isoelétrico. Podese considerar que o mapa protéico de características químicas (Tabela 1) aqui descrito constitui-se em um banco de dados de proteínas candidatas ao envolvimento com o processo apomítico, o qual poderá ser utilizado em futuros estudos de identidade protéica, buscando maior elucidação do sistema apomítico em embriões resultantes do cruzamento de Citrus sinensis e Poncirus trifoliata.

\section{CONCLUSÕES}

1) Plântulas apomíticas oriundas do cruzamento de Citrus sinensis e Poncirus trifoliata expressam um grupo de proteínas não expressas por plântulas zigóticas, de forma que algumas destas proteínas podem estar envolvidas no processo apomítico.
2) Existem diferenças na quantidade de expressão protéica de genes comuns a plântulas zigóticas e apomíticas.

\section{AGRADECIMENTOS}

\section{À FAPESP, pelo suporte financeiro do Projeto 98-14753/9.}

\section{REFERÊNCIAS BIBLIOGRÁFICAS}

BRADFORD, M. A rapid and sensitive method for the quantification of microgram quantities of proteins using the principle of protein dye binding. Analytical Biochemistry, Orlando, v.72, p.248-254, 1976.

CAMERON, J. W.; SOOST, R. K. Breeding and development in 75 years of citrus research. California Agricultulture, Oakland, v.36, p.4-6, 1982.

CROUCH, M. L. Non-zygotic embryos of Brassica napus L. contain embryospecific storage proteins. Planta, Heidelberger, v.156, p. 520-524, 1982.

DAVIES, F.S.; ALBRIGO, L.G. Crop production science in horticulture: citrus. Walkingford: CAB International, 1994. 254p.

DIJK, P. V.; DAMME, J. V. Apomixis technology and the paradox of sex. Trends in Plant Science, v.5, n.2, p.81-84, 2000.

FEY, S. J.; LARSEN, P. M. 2D or not 2D. Current Opinion in Chemical Biology, n.5, p. 26-33, 2001.

GOLDBERG, R. B.; BARKER, S. J.; PEREZ-GRAU, L. Regulation of gene expression during plant embryogenesis. Cell, Cambridge, v.56, p.149$160,1989$.

HURKMAN, W. J.; TANAKA, C. K. Solubilization of plant membrane proteins for analysis by two-dimensional gel electrophoresis. Plant Physiology, Sofia, v.81, p. 802-806, 1986.

IWAMASA, M.; JENO, I.; NISHIURA, M. Inheritance of nucellar embryony in citrus. Bulletin of the Horticultural Research, Shizuoka, v.7, p.1-8, 1967.

KOLTUNOW, A. M. Apomixis: embryo sacs and embryos formed without meiosis or fertilization in ovules. Plant Cell, Rockville, v.5, p.1245-1437, 1993.

KOLTUNOW,A. M. ; BICKNELL, R. A.; CHAUDHURY,A. M. Apomixis: Molecular strategies for the generation of genetically identical seeds without fertilization. Plant Physiology, Sofia, v.108, p.1345-1352, 1995.

KOLTUNOW, A. M.; HIDAKA; T., ROBINSON, S. Poliembriony in citrus: accumulation of seed storage proteins in seeds and in embryos cultured in vitro. Plant Physiology, Sofia, v.110, p.599-609, 1996.

LAEMMLI, U. K. Cleavage of structural proteins during the assembly of the head of bacteriophage T4. Nature, London, v.227, p.680-685, 1970.

LOPEZ, F. L. Proteome analysis: I. Gene products are where the biological action is. Journal of Chromatography, Amsterdam, n. 722. p.191-202, 1999.

MURASHIGE, T.;TUCKER, D. P. H. Growth factor requeriments of citrus tissue culture. Proceeding First International Citrus Symposium, Riverside, v.3, p.1155-1161, 1969.

NIJIS,A.P.M.;VANDIJIK, GE.Apomixis. In:HAYWARD, M.O; BOSEMARK, N.O; ROMAGOSA, I. (Ed.) Plant breeding: principles and prospect. New York: Chapman \& Hall, 1994.p.229-245.

NOGLER, G.A. Gametophytic apomixis. In: JOHRI, B. M.(Ed.) Embriology of angiosperms. Berlim: Springer Verlag, 1984. p. 475-518.

O'FARRELL, P. H. High resolution two-dimensional electrophoresis of proteins. Journal of Biological Chemistry, Baltimore, v.250, p.40074021, 1975.

PARLEVLIET, J.E.; CAMERON J.W. Evidence on the inheritance of nucellar embryony in Citrus. Proceedings of American Society for Horticultural Science, Washington, v.74, p.52-260, 1959.

PEACOCK, W. J. Genetic engeneering and mutagenis for apomixis in rice. Apomixis Newslett, v.4, p.3-7, 1992.

SAGHAI-MAROOF, M.A.; SOLIMAN, K.; JORGENSEN, R.A.;ALLARD, R. W. Ribossomal DNA spacerlength polymorphisms in barley: mendelian inheritance, chromossomal location, and population dynamics. Proceedings of the National Academy of Sciences, London, v.81, p. 8014-8018, 1984.

THOMAS, T. L. Gene expression during plant embriogenesis and germination: an overview. The Plant Cell, Rockville,. v.5, p.1401-1410, 1993. 